https://doi.org/10.19195/0137-1150.173.16

Data przesłania artykułu: 5.09.2019

Data akceptacji artykułu: 13.02 .2020

\author{
KATARZYNA GLINIANOWICZ
}

Instytut Slawistyki Polskiej Akademii Nauk, Warszawa, Polska

\title{
Gesty pańszczyźniane. Cielesny wymiar pamięci społecznej w prozie Iwana Franki*
}

\section{Wyparte mleczne rodzeństwo}

W latach osiemdziesiątych XIX wieku pisarz austriacki Leopold von Sacher-Masoch (1836-1895) oddawał się sentymentalnym wspomnieniom o swym lwowskim dzieciństwie:

Baśni, które opowiadała moja niania, pieśni ludowe, które śpiewała, o wiele głębiej wpłynęły na mój sposób myślenia, życie emocjonalne i charakter niż wszystkie moje późniejsze studia. [...] Raczej nie ma drugiego takiego narodu, posiadającego tak olbrzymią skarbnicę baśni, legend i pieśni ludowych, jak Małorusini ${ }^{1}$.

W tym czasie psychiatra Richard von Krafft-Ebing (1840-1902) na podstawie analizy wątków seksualnych w powieści Sacher-Masocha Wenus w futrze (Venus im Pelz, 1870) zdiagnozował nową jednostkę chorobową, nazywając ją masochi$\mathrm{zmem}^{2}$. Nie zauważył przy tym jej galicyjskiej genealogii.

Sacher-Masoch, syn habsburskiego prefekta policji lwowskiej, spędził w Królestwie Galicji i Lodomerii pierwsze dwanaście lat życia, dzięki czemu właśnie ta prowincja austriacka dostarczyła mu materiałów do kreowania nie tylko fikcji literackiej, lecz także własnej biografii. Prozaik fantazjował o swych ruskich przodkach, nazywał siebie Rusinem galicyjskim i wyznawał, że tę tożsamość wyssał

* Artykuł powstał w wyniku realizacji projektu badawczego o $\mathrm{nr}$. 2016/20/S/HS2/00584, finansowanego ze środków Narodowego Centrum Nauki.

${ }^{1}$ L. von Sacher-Masoch, Souvenirs. Autobiographische Prosa, Munich 1985, s. 43, za: L. Wolff, The Idea of Galicia: History and Fantasy in Habsburg Political Culture, Stanford 2010, s. 122. Jeśli nie zaznaczam inaczej, tłumaczenia są mojego autorstwa - K. G.

2 R. von Krafft-Ebing, Psychopathia Sexualis, przeł. M. Chojnacki, ,Schulz/Forum” 2016, nr 7, s. 121-155. 
z mlekiem swej mamki-Rusinki ${ }^{3}$. Szczególną atencją obdarzał ruskich chłopów, natomiast nie okazywał sympatii szlachcie polskiej. Spotkało się to z krytyką krakowskiego lekarza Leona Wachholza (1867-1942), który w wydanej w 1907 roku broszurce Sacher Masoch i masochizm dowodził, że to nie nabyty w Galicji „pierwiastek słowiański”, lecz „nieprawidłowa vita sexualis” pisarza stała się przyczyną jego nienawiści do szlachty polskiej, fetyszyzacji nie tylko futra i bicza, ale też ruskiego chłopa ${ }^{4} . \mathrm{Z}$ analizy Wachholza wynika, że „zdrowa” przestrzeń galicyjska nie mogła warunkować „chorej” osobowości pisarskiej autora Wenus w futrze.

Współczesny badacz dziejów Europy Wschodniej, Larry Wolff, argumentuje tymczasem, że grunt galicyjski wpłynął na seksualne preferencje bohaterów powieści Sacher-Masocha ${ }^{5}$. Przyszły pisarz spędził swe dzieciństwo w Galicji w latach $1838-1848$, gdy zachodziły tam istotne przemiany społeczne. Elity ruskie rozpoczynały wówczas konstruowanie własnej, odrębnej od polskiej, wspólnoty narodowej ${ }^{6}$, jednocześnie zaostrzały się konflikty między szlachtą a chłopami, których kulminacją była rabacja z 1846 roku w Galicji Zachodniej. Pamięć Sacher-Masocha o społecznych nierównościach, które przerodziły się w rzeź szlachty ${ }^{7}$, zbiegła się z habsburską reprezentacją Galicji jako części barbarzyńskiej Europy Wschodniej cywilizowanej przez Wiedeń. W jego literackiej przestrzeni społeczna przemoc i dominacja szlachty nad chłopstwem przybrała formę kompensacyjnego przekładu na motyw seksualnego panowania kobiety nad mężczyzną ${ }^{8}$.

Wspomnienia Sacher-Masocha o galicyjskim dzieciństwie implikują jeszcze jeden wątek dominacji i podporządkowania. Przyszły pisarz, jako dziecko urzędnika habsburskiego, został przystawiony do piersi mamki — ruskiej chłopki, przedstawicielki najniższej pod względem kulturowym, społecznym i płciowym warstwy galicyjskiej. Oznaczało to, jak rozumuje Wolff, że w tym samym czasie w jednej z podlwowskich wsi rosło jego ruskie mleczne rodzeństwo, którego nie

3 Por. M. Kłańska, Daleko od Wiednia: Galicja w oczach pisarzy niemieckojęzycznych 1772 1918, Kraków 1991, s. 120-134; А.-Г. Горбач, Украӥнська тематика у творчості Захер-Махзо$x a$, „Незалежний культурологічний часопис «Ї̈»” 2018, nr 87: Львів епохи Мазоха 1840-1860, s. 42-61; Л. Полубояринова, Леопольд фон Захер-Мазох - австрийский писатель эпохи реализма, Санкт-Петербург 2006, s. 99-100; В. Чернецький, Украӥнці, росіяни та Мазохів спадок, „Критика” 2005, nr 9, s. 11-13.

${ }^{4}$ L. Wachholz, Sacher Masoch i masochizm: szkic literacko-psychiatryczny wedlug collegium publicum, Kraków 1907, s. 32.

5 L. Wolff, The Idea of Galicia..., s. 111-157.

${ }^{6}$ Notabene temat ten podjął Sacher-Masoch w opowiadaniu Sasha und Saschka z 1885 roku. Zob. M. Kłańska, Daleko od Wiednia..., s. 120-124.

${ }^{7}$ Doniesienia o rabacji zapisały się w pamięci Sacher-Masocha, o czym świadczą jego wspomnienia. Jako dziesięcioletni chłopiec miał spotkać we Lwowie samego przywódcę powstania chłopskiego - Jakuba Szelę, gdy ten zmierzał na Bukowinę. Ponadto ojciec pisarza, Leopold von Sacher-Masoch, był autorem opracowania na temat wydarzeń z 1846 roku. Zob. T. Szubert, Jak(ó)b Szela: (14) 15 lipca 1787-21 kwietnia 1860, Warszawa 2014, s. 17, 162.

8 Zob. L. Wolff, The Idea of Galicia..., s. 112-114. 
było dane mu poznać. Mleczny bliźniak Sacher-Masocha wyrastał jako członek emancypującego się pokolenia Rusinów9

Proponuję zastanowić się, jak przedstawiciel kolejnej generacji Rusinów/ Ukraińców ${ }^{10}$, Iwan Franko (1856-1916), przepracowywał w swej prozie te same co Sacher-Masoch galicyjskie traumy ${ }^{11}$. Nawiązując do badań Paula Connertona nad związkami między ciałem a pamięcią społeczną, postawię pytanie o to, w jaki sposób pańszczyźniana „przeszłość osadziła się w ciele”12 jego bohaterów.

\section{Ruskie ciało obce}

Zanim przejdę do prozy Franki, zatrzymam się nad jego literacko-społecznymi spostrzeżeniami opublikowanymi dwadzieścia lat po rabacji:

Rok 1846 zwrócił od razu uwagę całego polskiego społeczeństwa na polski lud, silniej, niżby to mogła uczynić najwspanialsza epopeja. Jedni przeklinali ten lud, drudzy przeczyli jego polskości, lecz wszyscy o nim mówili, myśleli o nim, szukali motywów jego postępowania $^{13}$.

Zwrot w dyskursie chłopskim postawił elity polskie przed koniecznością symbolicznego pokonania głównego czynnika krwawych zapustów - społecznego rozziewu między szlachtą a rzymskokatolickim chłopstwem. Jego przezwyciężenie stawało się warunkiem koniecznym w domykaniu wyobrażanej wspólnoty narodowej tych elit. W owym procesie ważną rolę odgrywał także wątek ruski.

Od momentu powołania Głównej Rady Ruskiej na fali Wiosny Ludów projekt „odradzania” Polski przy wsparciu lojalnego duchowieństwa greckokatolickiego typu gente Rutheni, natione Poloni i chłopstwa ruskiego stawał się coraz bardziej nieosiągalny. Pogłębiające się polsko-ruskie różnice społeczne, obrządkowe, a następnie narodowe spowodowały, że ruscy „chłopi i popi” stawali się dla Polaków tożsamościowym Innym. Tymczasem właśnie ten Inny rekompensował napięcia między szlachtą a rzymskokatolickim chłopstwem. Dlatego — choć rzeź ogarnęła ziemie Galicji Zachodniej — pisarze polscy swe lęki rabacyjne projektowali na

9 Ibidem, s. 122.

10 Formę „Rusini/Ukraińcy” stosuję dla określenia początku procesu społecznej i narodowej transformacji Rusinów w Ukraińców na przełomie XIX i XX wieku — zob. m. in. A. Wilson, Ukraińcy, przeł. M. Urbański, Warszawa 2002, s. 111. Często, zależnie od tożsamości autora lub bohatera, używam tylko kategorii „Rusin” lub „Ukrainiec”.

11 Warto nadmienić, że Franko w prywatnej korespondencji do swej żony Olhy Franko dał lakoniczną i negatywną ocenę twórczości Sacher-Masocha: „Він про Галичину бреше несотворенні речі, се звісно цілому світу, крім французів і москалів", І. Франко, До О. Ф. Франко [Львів, близько 10 серпня 1891 р.], [w:] idem, Зібрання творів у п'ятдесяти томах, t. 49, Київ 1986, s. 286. Możliwe, że Franko projektował na twórczość Sacher-Masocha swój krytyczny stosunek do literatury galicyjskich rusofilów, którzy chętnie publikowali tłumaczenia jego utworów w swych periodykach. Zob. М. Л. Вальо, Захер-Мазох і Україна, „Всесвіт” 1994, nr 3, s. 152-155.

12 P. Connerton, Jak społeczeństwa pamiętaja, przeł. M. Napiórkowski, Warszawa 2012, s. 145.

13 I. Franko, Chłop polski w świetle poezji polskiej (,,Placówka”, powieść Bolesława Prusa, Warszawa 1886), „Ruch” 1887, nr 9, s. 278. 
lokalny ukraiński wschód ${ }^{14}$. Andrzej Rydel ${ }^{15}$ w wydanym w 1848 roku cyklu poetyckim Krwawa taźnia w Galicyi ${ }^{16}$ związał rzeź humańską z rabacją galicyjską, zestawił hajdamaków Gontę i Żeleźniaka z Szelą. Natomiast Jan Zachariasiewicz (1823-1906) w powieści Jarema z 1863 roku przedstawił tytułowego bohatera ruskiego chłopa, który przy wsparciu plebanii greckokatolickiej i administracji austriackiej inicjuje walkę z dworem o serwituty — jako wiernego „ucznia szkoły, z której wyszedł Szela i towarzysze..." ${ }^{\prime 17}$. Ruska elita duchowna, zwana świętojurcami, w powieści Mariana Gorzkowskiego (1830-1911) Księdzówna z 1877 roku została pokryta antyszlachecką „pleśnią i brudem”18.

Rusko-polską tożsamościową linię demarkacyjną pisarze polscy wyznaczali również na cielesnej powłoce Rusinów. Prezentowali ich w postaci rozpustnego księdza ruskiego, wywołującej żądzę Rusinki, ciemnej, żywiołowej masy chłopstwa $^{19}$. Obce ciało Rusina i Rusinki stało się metaforą galicyjskich konfliktów społecznych oraz transformacji tożsamościowych. Rewers tych cielesnych reprezentacji zaistniał w tekstach ukraińskich.

\section{„Nisko kłaniać się każdemu panu...”}

Sposoby zachowywania się, gesty, pozycje ciała zdaniem Connertona są nie tylko formą reprezentacji przynależności społecznej, płciowej i kulturowej jednostki, lecz także systemem mnemotechnicznym ${ }^{20}$. Zestaw określonych praktyk cielesnych jest bowiem kształtowany w toku historycznego długiego trwania (czego dowodził Norbert Elias w analizie procesu cywilizacji ${ }^{21}$ ). Zewnętrzna powłoka może zatem nosić na sobie ślady wzorców zarówno władzy, jak i podległości, które intencjonalnie lub nieświadomie są przyswajane i reprodukowane przez

14 Zdaniem historyka Andriya Zayarnyuka: „projekcja własnej nieefektywnej taktyki na Rusinów była częścią większego polskiego narodowego projektu zapominania 1846 r. Polskie zmaganie się z 1846 r. jest istotne dla zrozumienia, dlaczego Rusini nie stali się Polakami. Problem nie dotyczy tylko odrzucenia tożsamości polskiej przez Rusinów [...]. Możliwe, że wytłumaczenia należy szukać również w pozycji Polaków, którym nie udało się znaleźć miejsca w swym projekcie narodowym dla owego »wschodu«. W traumatycznej optyce działaczy polskich po 1846 r. różnice społeczne zaczęły się łączyć z etnicznymi”, idem, Framing the Ukrainian Peasantry in Habsburg Galicia, 1846-1914, Edmonton 2013, s. 29-30.

15 Nie udało mi się ustalić lat urodzin i śmierci autora.

16 A. Rydel, Krwawa łaźnia w Galicyi w dniu 19, 20, 21 lutego 1846 r. odbyta, Kraków 1848.

17 J. Zacharyasiewicz, Jarema, [w:] idem, Wybór pism Jana Zacharyasiewicza, t. 11, Warszawa 1888 , s. 157.

18 M. Gorzkowski, Księdzówna: powieść galicyjska, Kraków 1877, s. 164.

19 Motywy te, oprócz wspomnianych powieści, są też w utworach: Czarny Matwij (1860) Walerego Łozińskiego (1837-1861), Św. Jur (1862) Jana Zachariasiewicza, Choroby Galicji w latach od 1866-1876 podpatrzone i opowiedziane przez dukata (1876) Józefa Rogosza (1844-1896), Do celu. Obrazek z życia Rusinów galicyjskich (1893) Kajetana Abgarowicza (1856-1909).

20 Zob. P. Connerton, Jak społeczeństwa..., s. 170.

21 Zob. N. Elias, O procesie cywilizacji: analizy socjo- i psychogenetyczne, przeł. T. Zabłudowski, K. Markiewicz, Warszawa 2011. 
kolejne pokolenie. Ciało w pozycji wertykalnej lub horyzontalnej, zgarbione lub z wysoko podniesioną głową traktuję jako metafory cielesne odzwierciedlające doświadczanie przestrzeni i jej wpływ na jednostkę ${ }^{22}$. Podobne tropy somatyczne wykorzystywał Franko. Najczęściej protagonistami jego powieści są przedstawiciele pierwszego pokolenia inteligencji ruskiej/ukraińskiej o chłopskim rodowodzie. Ich ciała, jak również ciała Innych — chłopów czy szlachty — z którymi wchodzą w interakcję, odtwarzają z zastosowaniem cielesnych metafor historię rusko/ukraińsko-polskich pragnień i antagonizmów.

Zaangażowany w proces emancypacji chłopów adwokat Jewhenij Rafałowycz z utworu Перехресні стежки (1900) nieustannie konfrontuje się z ich pańszczyźnianą mentalnością. Chłopi, choć prawnie uwłaszczeni, poddają się (auto)zniewoleniu pod względem psychicznym, ekonomicznym oraz cielesnym, co w utworze przejawia się w ich gestach uniżenia:

А он під брамою купка селян - ще обпалених сонцем від літа, але вже скулених, обдертих, присілих порохом, виголоднілих. Стоять $з$ шапками в руках, видно, ждуть пана „жонци”, чи прийме завтра на роботу до молочення або до горальні, — хоч по п’ятнадцять крейцарів денно. Коли Свгеній переїздив попри них, вони всі мов на команду низенько поклонилися йому, хоч, ніхто з них не знав його. „Пан” - i вони з віку-правіку привикли низько кланятися всякому панові; се одинока „наука”, одинока „цивілізація”, яку передав їм двір ${ }^{23}$.

U bohatera — przedstawiciela młodej elity — gesty pańszczyźniane chłopstwa, z którego się wywodzi, wywołują poczucie wstydu i niepewności. Spotkanie z twarzą karnie pochylonego chłopa narusza morale i destabilizuje nie całkiem jednak wyemancypowane ,ja” protagonisty. Chłopskie ciało, niby należące do innego, ale jakże swojskie, uporczywie przypomina mu o własnym pochodzeniu. Narracje Franki rozpoznają gesty ruskiej podrzędności, by następnie z nimi zmagać się, zacierać, wypierać. Cechy te, sięgając po kategorię Julii Kristevej24, to abject, w tym przypadku rusko-ukraiński abject, czyli to, co jest między pańszczyźnianym przedmiotem ruskim a niezależnym ukraińskim podmiotem. Abject jest bytem niepewnym, który podmiot powinien odrzucać, zagraża on bowiem jego stabilnej tożsamości: przypomina mu, że dziedziczy podporządkowanie rodziców.

\section{Pańszczyzna erotyczna}

Kulminacją tożsamościowego dramatu stają się cielesne relacje bohatera Franki z kobietą. W ramach tych relacji staje on przed wyborem między zadowoleniem własnych seksualnych pragnień a sublimowaniem ich w realizację idei społecznych. Centralną figurą jest tu postać Polki — z nią Rusin/Ukrainiec konfrontuje swą dojrzałość społeczną i narodową.

22 Zob. P. Connerton, Jak społeczeństwa..., s. 148.

23 I. Франко, Перехресні стежки, [w:] idem, Зібрання творів..., t. 20, Київ 1979, s. 288289.

${ }^{24}$ Zob. J. Kristeva, Potęga obrzydzenia: esej o wstręcie, przeł. M. Falski, Kraków 2007. 
Typowe dla tej sytuacji kontrolowanie własnego ciała interpretuję jako lęk przed tym, że jego poza i gesty zdradzą chłopskie pochodzenie bohatera. Jak zaznacza bowiem Connerton, kultura cielesnych zachowań warstwy wysokiej to dziedziczony kapitał symboliczny. Stąd „naturalność” i swoboda szlacheckich manier oraz celebrowania aktów, które mają za zadanie kamuflować zaspokajanie potrzeb fizjologicznych. Natomiast jednostki wywodzące się z warstw niższych nie mają owego kapitału, zatem brakuje im szlacheckiej swobody, a w jej miejsce pojawia się zażenowanie, wstydliwość, nieustanna kontrola tego, co należy do sfery cielesnej $^{25}$. To dlatego ciało Borysa Hraba z powieści Franki Не спитавши броду $\left(1927^{26}\right)$ w ramionach szlachcianki Michońskiej ujawnia jego społeczny rodowód:

За дотиком іï̈ пухких рук до його руки у хлопця сильно забилось серце, зашуміло в голові, він не знав, не тямив, що з ним діється.

- Ах ви, дикий, дикий, - шептала йому між тим до уха пані Міхонська [...].

Несамовитий жар тих очей хвилею поллявся немов аж в саме серце, в саму душу Бориса, покотився по жилах, потряс нерви гарячковою дрожжю. Його віддих стався швидкий і тяжкий, немов яка змора давила його.

- Пані, змилуйтесь, пустіть мене! — прошепотів він в одчаю, не маючи сили вирватись з їі обнять. [...].

- Ха, ха, ха! От дурний! От чого налякався! Схаменись, дурний хлопче! Не бійся! Адже я не з'їсти тебе хочу, хоч з'їла б, якби могла! Так люблю! А він боїться! Ну, диви, що тут страшного? Га? Га? Га?

I за кожним словом вона своїми калиновими, як жар палаючими, губами цілувала лиця, очі, губи Борисові. Хлопець до решти стратив пам'ять.

Розбитий, знівечений, до глибини душі пронятий встидом, після безсонної ночі явився на другий день (а була неділя) Борис у Міхонського 27.

Kreując polską bohaterkę, pisarz sięgnął po obraz kobiety fatalnej, który w literaturze monarchii habsburskiej upowszechnił Sacher-Masoch ${ }^{28}$. Obraz Michońskiej to reminiscencja Wandy von Dunajew z Wenus $w$ futrze i podobnie stanowi on wcielenie lęków oraz pragnień, jednak tym razem nie szlachcica Seweryna von Kusiemskiego, lecz chłopskiego syna, gimnazjalisty Hraba. Dominująca kulturowo Polka seksualnie kolonizuje „dzikiego” Rusina/Ukraińca. Tę wyrafinowaną

25 P. Connerton, Jak społeczeństwa..., s. 174.

26 Podaję datę pierwszej publikacji niedokończonej powieści. Franko pisał utwór w latach osiemdziesiątych XIX wieku.

27 I. Франко, Не спитавши броду, [w:] idem, Зібрання творів..., t. 18, Київ 1978, s. 343.

28 Zob. S. Hake, Femme fatale, [w:] The Feminist Encyclopedia of German Literature, red. F. U. Eigler, S. Kord, Westport, CT-London 1997, s. 164. Choć źródła tego motywu w literaturze rusko-ukraińskiej można odnaleźć jeszcze w staroruskiej opowieści O Mojżeszu-Węrzynie z Pateryku Kijowsko-Pieczerskiego (XIII-XVII wiek), w której tytułowy bohater — członek drużyny księcia rostowskiego Borysa, wzięty do niewoli w czasie wyprawy kijowskiej Bolesława Chrobrego — jest obiektem pożądania zamożnej Polki. Gdy Mojżesz odrzuca jej zaloty, ta w porywie zemsty każe go wykastrować (notabene opowieść ta jest aluzją do starotestamentowej historii o żonie urzędnika egipskiego Potifara, która próbuje uwieść niewolnika swego męża — Józefa). W literaturze nowożytnej nawiązuje do niego między innymi Mikołaj Gogol (1809-1852) w Tarasie Bulbie (Tapac Бульба, 1835, 1842). 
szlachecką kochankę pobudza zawstydzenie jej obiektu pożądania, wobec którego może uczynić wyłom w systemie patriarchalnego podporządkowania kobiet i zasmakować dominacji.

W ciele — jak uważał Foucault — odbijają się dzieje pragnień i konfliktów ${ }^{29}$. Scena Franki z dominującą seksualnie Polką oraz pasywnym ciałem Rusina/Ukraińca to metafora stosunków galicyjskich. Współżycie szlachcianki z emancypującym się chłopem nie przekracza granic społecznych i narodowych: seks między nimi jest możliwy, ale nie na równoprawnych zasadach, ze względu na wpisaną w niego władzę. Jednak doświadczenie cielesne wzmacnia świadomość Hraba, który z czasem - po przejściu społecznej i męskiej indywiduacji — odrzuca kolejne zaloty Michońskiej, a swe pragnienia seksualne sublimuje we własną aktywność społeczną.

\section{Gdy szlachta staje się naga}

Kapitał symboliczny szlachty, jak każdej warstwy wysokiej, pozwolił jej wypracować techniki kulturowej sublimacji własnej natury biologicznej i tym samym uważać się za predestynowaną do dominacji nad naturą społeczną ${ }^{30}$. Jednak narracje Franki przenicowują ten szlachecki dorobek: z ciała szlachty pozbawionego norm kultury wysokiej pozostaje naga fizjologia. Dzieje się tak ze szlachcicem Rębą, bohaterem Не спитавши броду, który największą przyjemność życiową czerpie z pornografii i napełniania żołądka:

Скоро тільки стіл був накритий, він сів на своє місце, взяв ложку до рук і з ідіотичним виразом лиця впер очі у вазу з росолом, що димилась насеред стола. Щезли порнографічні тумани, остався тільки пережовуючий звір ${ }^{31}$.

Franko, opisując świat galicyjski w trakcie zmian społecznych, stworzył szlacheckie „ciało groteskowe" ${ }^{32}$. Wykonuje ono biologiczne czynności jedzenia, spółkowania i dzięki temu staje się żyznym gruntem dla konstytuowania nowych relacji ciał galicyjskich. Obsceniczność i wątki skatologiczne zhańbiły dystynkcję

29 Nawiązuję do stwierdzenia Foucaulta: „Na ciele znajdujemy stygmat minionych zdarzeń, podobnie jak w nim rodzą się pragnienia, słabości i błędy; w nim się także one łączą i nagle uzyskują wyraz, lecz w nim również się rozchodzą, rozpoczynają walkę, przyćmiewają nawzajem i zmagają w nieokiełznanym konflikcie”, idem, Nietzsche, genealogia, historia, [w:] idem, Filozofia, historia, polityka: wybór pism, przeł. D. Leszczyński, L. Rasiński, Warszawa-Wrocław 2000, s. 120.

${ }^{30}$ Zdaniem Connertona warstwy wysokie dzięki wypracowanej w procesie cywilizacji „,mnemotechnice ciała” mogły swobodnie ukrywać „materialną rzeczywistość aktu konsumpcji”, idem, Jak społeczeństwa..., s. 164.

31 I. Франко, Не спитавши..., s. 446.

32 Nawiązuję do Bachtinowskiego „ciała groteskowego” jako metafory „świata na opak”, M. Bachtin, Twórczość Franciszka Rabelais'go a kultura ludowa średniowiecza i renesansu, przeł. A. i A. Goreniowie, oprac., wstęp, komentarze, weryfikacja przekł. S. Balbus, Kraków 1975, passim. 
społeczną wytwarzaną przez pokolenia szlachty i tym samym otworzyły przestrzeń emancypacji Rusinów/Ukraińców ${ }^{33}$.

Rozpoznawanie i zacieranie gestów pańszczyźnianych przez bohaterów Franki, a następnie redukcja galicyjskich dystynkcji społecznych w wyniku sprowadzenia szlachty do ciała biologicznego służyły dążeniom owych bohaterów do stabilizowania własnej podmiotowości społeczno-narodowej. Przeanalizowane strategie literackie były częścią formowania własnego kapitału symbolicznego, który miał gwarantować równorzędne interakcje kulturowe elit ukraińskich ze sprawującymi władzę w Galicji elitami polskimi. Wyprostowane, podporządkowane sobie ciała literackich bohaterów bez oporów, zażenowania i poczucia wstydu wchodzące w przestrzeń płciową, społeczną, polityczną i ekonomiczną, przekonująco świadczyły o postępie ukraińskiej emancypacji. Potwierdzą to też niebawem przeformułowane relacje seksualne ze swoim i Innym, w które bohaterowie prozy modernistycznej Olhy Kobylańskiej (1863-1942) czy Mychajła Jackiwa (1873-1961) wejdą z okiełznanymi gestami pańszczyźnianymi i mniejszymi obawami odnośnie do destabilizacji swej tożsamości.

\section{Bibliografia}

Bachtin M., Twórczość Franciszka Rabelais'go a kultura ludowa średniowiecza i renesansu, przeł. A. i A. Goreniowie, oprac., wstęp, komentarze, weryfikacja przekł. S. Balbus, Wydawnictwo Literackie, Kraków 1975.

Connerton P., Jak społeczeństwa pamiętaja, przeł. M. Napiórkowski, Wydawnictwa Uniwersytetu Warszawskiego, Warszawa 2012.

Černec'kij V., Ukraïncì, rosiâni ta Mazohì spadok, „Kritika” 2005, nr 9.

Elias N., O procesie cywilizacji: analizy socjo- i psychogenetyczne, przeł. T. Zabłudowski, K. Markiewicz, Wydawnictwo W.A.B., Warszawa 2011.

Foucault M., Nietzsche, genealogia, historia, [w:] idem, Filozofia, historia, polityka: wybór pism, przeł. D. Leszczyński, L. Rasiński, Wydawnictwo Naukowe PWN, Warszawa-Wrocław 2000.

Franko I., Chłop polski w świetle poezji polskiej (,, Placówka”, powieść Bolesława Prusa, Warszawa 1886), „Ruch” 1887, nr 9.

Franko İ., Do O. F. Franko [L'vì, bliz'ko 10 serpnâ 1891 r.], [w:] idem, Zibrannâ tvorìv u p âtdesâti tomah, t. 49, Naukova dumka, Kiïv 1986.

Franko Ì., Ne spitavši brodu, [w:] idem, Zibrannâ tvorìv u p âtdesâti tomah, t. 18, Naukova dumka, Kiïv 1978.

Franko Ì., Perehresnì stežki, [w:] idem, Zibrannâ tvorìv u p âtdesâti tomah, t. 20, Naukova dumka, Kiïv 1979.

Franko İ., Petriï i Dovbusikiki, [w:] idem, Zibrannâ tvorìv u p âtdesâti tomah, t. 14, Naukova dumka, Kiïv 1978.

33 Analogiczne obrazy są w innych powieściach Franki, na przykład w Петрії і Довбущуки — panna młoda, szlachcianka Dozia Kralińska, jest porównana do „білого їдовитого стрімкого сморжа, що, прекрасний зверху, внутрі криє гниль і вроджене зіпсуття" (I. Франко, Петрії і Довбущики, [w:] idem, Зібрання творів..., t. 14, Київ 1978, s. 168) oraz Перехресні стежки: Rafałowyczowi w obecności zdemoralizowanego Polaka Stalskiego zdaje się, że „заглядає в пивницю, повну гнилі і поганого хробацтва" (s. 210).

Slavica Wratislaviensia 173, 2020

(C) for this edition by CNS 
Gorbač A. G., Ukraïns'ka tematika u tvorostì Zaher-Mahzoha, „Nezaležnij kul'turologičnij časopis «Ï̀»" 2018, nr 87: L'vìv epohi Mazoha 1840-1860.

Gorzkowski M., Księdzówna: powieść galicyjska, Druk W. Korneckiego, Kraków 1877.

Hake S., Femme fatale, [w:] The Feminist Encyclopedia of German Literature, red. F. U. Eigler, S. Kord, Greenwood Press, Westport, CT-London 1997.

Kłańska M., Daleko od Wiednia: Galicja w oczach pisarzy niemieckojęzycznych 1772-1918, TAiWPN „Universitas”, Kraków 1991.

Krafft-Ebing R. von, Psychopathia Sexualis, przeł. M. Chojnacki, „Schulz/Forum” 2016, nr 7.

Kristeva J., Potęga obrzydzenia: esej o wstręcie, przeł. M. Falski, Wydawnictwo Uniwersytetu Jagiellońskiego, Kraków 2007.

Poluboârinova L., Leopol'd fon Zaher-Mazoh — avstrijskij pisatel' èpohi realizma, Nauka, Sankt-Peterburg 2006.

Rydel A., Krwawa łaźnia w Galicyi w dniu 19, 20, 21 lutego 1846r. odbyta, Drukarnia Uniwersytecka, Kraków 1848.

Szubert T., Jak(ó)b Szela: (14) 15 lipca 1787-21 kwietnia 1860, Wydawnictwo „DiG”, Warszawa 2014.

Val'o M. L., Zaher-Mazoh ì Ukraïna, „Vsesvìt” 1994, nr 3.

Wachholz L., Sacher Masoch $i$ masochizm: szkic literacko-psychiatryczny wedlug collegium publicum, Drukarnia Uniwersytetu Jagiellońskiego, Kraków 1907.

Wilson A., Ukraińcy, przeł. M. Urbański, Świat Książki, Warszawa 2002.

Wolff L., The Idea of Galicia: History and Fantasy in Habsburg Political Culture, Stanford University Press, Stanford 2010.

Zacharyasiewicz J., Jarema, [w:] idem, Wybór pism Jana Zacharyasiewicza, t. 11, Gebethner i Wolff, Warszawa 1888.

Zayarnyuk A., Framing the Ukrainian Peasantry in Habsburg Galicia, 1846-1914, CIUS Press, Edmonton 2013.

\section{Serf Gestures. Bodily Dimension of Social Memory in Ivan Franko's Prose}

Summary

The article is an analysis of the representations of body in selected novels authored by the Ukrainian writer, Ivan Franko, which form a part of the Galician discourses about the memory of serfdom. As the main theoretical context, the author of the article adopts Paul Connerton's concept of the body as a medium of social memory. She pays attention to how the characters in Franko's novels - representatives of the first generation of Ruthenian/Ukrainian intelligentsia of the peasant origin of the 1870-1890s - recreate past serf relations between the Ruthenian peasantry and Polish nobility with the help of bodily poses, gestures, and interactions. The author concludes by stating that the bodily dimension of memory about serfdom forces characters to have special control over their body. The control becomes part of the process of emancipation of own social-cum-national identity.

Keywords: Ivan Franko, body, memory, Galicia, serfdom

Slavica Wratislaviensia 173, 2020

(C) for this edition by CNS 


\section{Жести панщини. Тілесний вимір суспільної пам’яті в прозі Івана Франка}

\section{Резюме}

У статті здійснено аналіз репрезентацій тілесности в вибраних повістях Івана Франка, що $\epsilon$ частиною галицьких дискурсів пам'яті про панщину. Теоретична основа — це концепція тіла як носія суспільної пам'яти, запропонована Полом Каннертоном. Звернено увагу на те, як у Франкових творах представники першого покоління руської/української інтелігенції 70-80-х рр. ХІХ ст., користуючись позою, жестом та тілесною взаємодією, відтворюють минулі панщинні відносини між руським селянством та польською шляхтою. У висновках указано, що вписана в тіло пам'ять про панщину примушує Франкових героїв особливо ревно контролювати свою тілесність. Цей контроль стається частиною процесу емансипації їхньої суспільної та національної ідентичности.

Ключові слова: Іван Франко, тіло, пам’ять, Галичина, панщина 